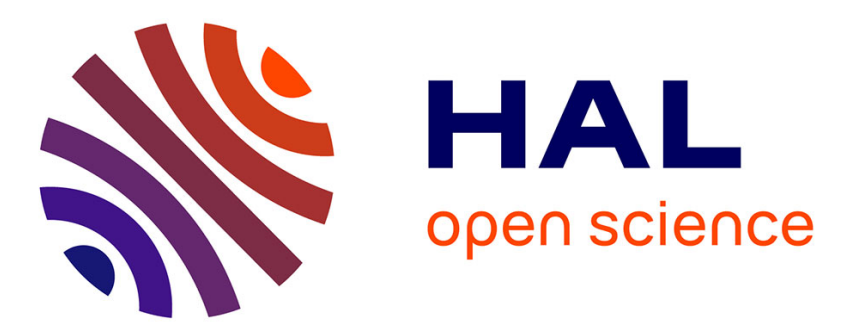

\title{
Recent developments in X-ray projection microscopy and X-ray microtomography applied to materials science
}

J. Cazaux, D. Erre, D. Mouze, J. Patat, S. Rondot, A. Sasov, P. Trebbia, A. Zolfaghari

\section{- To cite this version:}

J. Cazaux, D. Erre, D. Mouze, J. Patat, S. Rondot, et al.. Recent developments in X-ray projection microscopy and X-ray microtomography applied to materials science. Journal de Physique IV Proceedings, 1993, 03 (C7), pp.C7-2099-C7-2104. 10.1051/jp4:19937334 . jpa-00251981

\section{HAL Id: jpa-00251981 https://hal.science/jpa-00251981}

Submitted on 1 Jan 1993

HAL is a multi-disciplinary open access archive for the deposit and dissemination of scientific research documents, whether they are published or not. The documents may come from teaching and research institutions in France or abroad, or from public or private research centers.
L'archive ouverte pluridisciplinaire HAL, est destinée au dépôt et à la diffusion de documents scientifiques de niveau recherche, publiés ou non, émanant des établissements d'enseignement et de recherche français ou étrangers, des laboratoires publics ou privés. 


\title{
Recent developments in X-ray projection microscopy and X-ray microtomography applied to materials science
}

\author{
J. CAZAUX, D. ERRE, D. MOUZE, J.M. PATAT, S. RONDOT, A. SASOV, P. TREBBIA and \\ A. ZOLFAGHARI
}

LASSI, GRSM, Faculté des Sciences, BP. 347, 51062 Reims, France

\begin{abstract}
After a long period of sleeping, there is recently a spectacular revival of X-ray microscopy due to the progress in X-ray sources (synchrotron radiation), X-ray optics, and X-ray detectors. However most of the attempts in this field concern the use of soft X-rays to observe, with an improved resolution, biological specimens in their wet environment. In opposition to these trends, we try to demonstrate in this paper the interest of using X-ray microscopy to materials science by applying the old principle of shadow microscopy (but with modern detectors such as CCD cameras) with harder X-rays. The excellent linearity, speed of acquisition and large dynamic of CCD cameras combined to the intrinsic advantage of X-rays "to see" inside thick specimens allows one to obtain digital images (for quantification), to follow dynamic processes (such as solid /solid diffusion) and to perform 3 - dimensional reconstruction of the object by X-ray microtomography. The performance of this renewed technique is indicated and illustrated by various examples.
\end{abstract}

\section{INTRODUCTION}

Over many other microscopies, the advantage of X-ray microscopy is its ability to observe thick specimens (from a few microns up to few millimeters) even set in selected environments (liquids or gases). After the early developments in the sixties [1,2] followed by a long period of sleeping, the last ten years are characterized by a renewed interest for this microscopy, which can be measured by the number of international conferences devoted to this technique [3-5] .

The recent developments in this field are related to the use of new X-ray sources such as (mainly but not only) synchrotron radiation and to the use of new focusing elements such as Fresnel zone plates or multilayer structures. As a whole, the main efforts concern the improvement of the lateral resolution of the microscopes in order to observe biological specimens using soft X-rays photons. A good example of these trends has been illustrated recently by the investigation of the distribution of DNA in chromosomes with a lateral resolution of $55 \mathrm{~nm}$ and the use of photons in the 285-590 eV interval [6].

The way followed by our laboratory is in the opposite direction. It consists in using harder Xrays $(1-25 \mathrm{keV})$ in a laboratory equipment based on the principles of the old shadow microscopy for applications in materials science. With respect to the microscopes as operated 
in the sixties, one of the main technical improvements is the use of a modern detector, a CCD camera (instead of photographic plates). This type of detector is characterized by an excellent linearity, a large dynamic range $\left(3.10^{4}\right)$ and a good sensitivity. Its performance allows one to obtain digital images in a few seconds (instead of few tens of minutes with photographic plates). These images can be processed and quantitative analytical X-ray microscopy is possible with also the 3-D reconstruction of the objects ( $x$-ray microtomography) and the acquisition of series of images related to time-dependant phenomena (chronomicroscopy). The goal of the present paper is to illustrate the potentiality of this type of microscope in the investigation of rather thick materials even if the lateral resolution is limited to the micron range.

\section{THE INSTRUMENT}

Fig. 1 (left) shows the schematic arrangement of our instrument. With respect to the instrument built by Cheng et al [7], (Fig. 1, right) the advantage of this arrangement is that it is based on simple modifications of a S.E.M. that keeps the possibility of obtaining secondary electron images and EDS analysis of the specimen. It is also possible to change, in a few seconds, the nature of the target generating the incoming X-ray beam in order to obtain rapidly different images of the same specimen using different radiations. This possibility opens the way to analytical X-ray microscopy and the corresponding elemental mapping. It also permits one to select the radiation that optimises the signal-to-noise ratio as a function of the thickness and of the composition of the specimen [8]. The advantage of Cheng's arrangement is that the specimen is outside the vacuum chamber whereas we have to put it into hermetic cells for its investigation into liquid or gaseous environments [9].

For quantitative imaging and following the well known Beer's law $\left(I=\mathrm{I}_{0} \mathrm{e}^{-\mu \mathrm{t}}\right.$ with $\mu$ : linear absorption coefficient and $t$ : specimen thickness), 3 successive images have to be recorded ; the first, $B$, without neither the specimen nor the beam (to obtain the dark current of the CCD alone) ; the second one $\mathrm{E}$, with the X-ray beam on but without the specimen (to obtain, for each pixel, the incident photon beam intensity) and the third one, $I$, with the incident $X$-ray and the specimen. Taking next, pixel by pixel, the $\log$ of the ratio (I-B)/(E-B) a $\mu$ t map of the specimen may be then deduced.
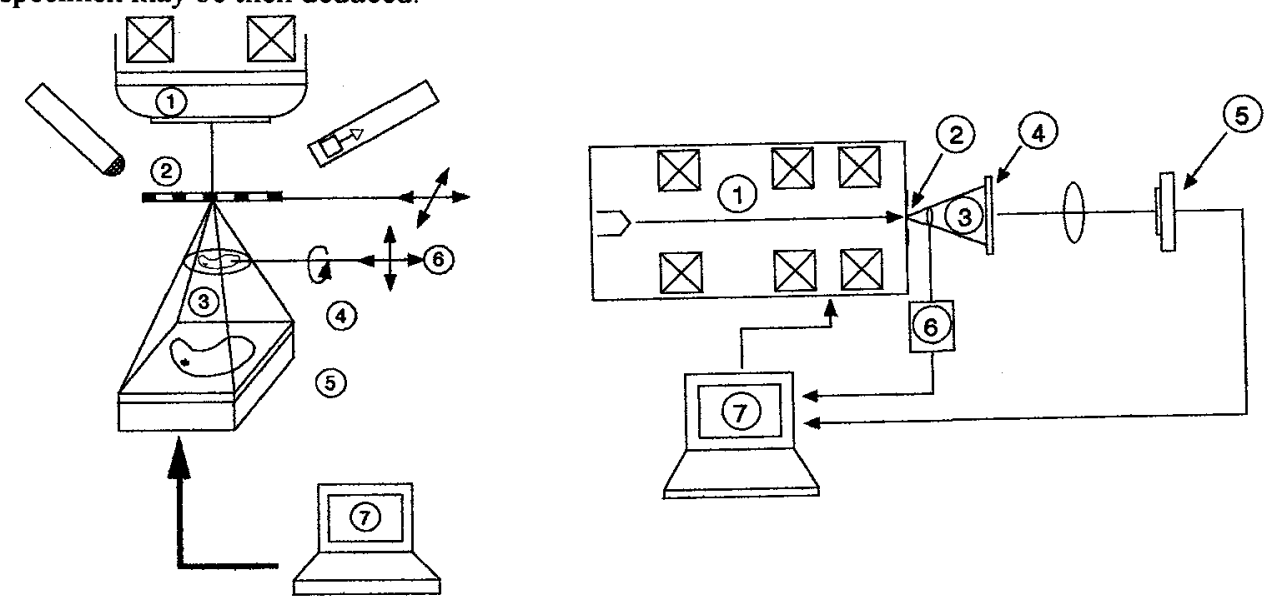

Fig.1 :Diagrammatic representation of two X-ray shadow projection X-ray microscopes and microtomographs. Left : our laboratory arrangement [8][9]; right : arrangement of Cheng et al [7]. 1 : Scannable electron beam ; $2: \operatorname{target} ; 3:$ X-ray beam ; $4:$ Phosphor screen ; 5 : Cooled CCD camera ; 6 : stepping motor for specimen rotation ; $7:$ Image acquisition. 
Such a treatment has been applied to the image shown in Fig. 2 in order to illustrate the high sensitivity of X-ray microscopy for the detection of a medium element embedded in a light element matrix. In such a case (Cu detection in an $\mathrm{Al}$ matrice) the detection limit is in the percent range but it can be pushed down to the $\sim 10 \mathrm{ppm}$ range for lighter matrices such as carbon or the oxygen of water [8].

Fig. 3 illustrates the ability of the technique to observe in a non-destructive way solid/solid interfaces (here $\mathrm{SiC} / \mathrm{ZrO}_{2}$ interfaces) even when the specimen is surrounded by an environment different from the vacuum (air into a sealed glass tube in Fig.3).

The geometry of our experimental arrangement provides a highly divergent X-ray beam illumination so that Kossel patterns can be produced by monocrystalline specimens. An example of digital acquisition of such a pattern (in a few seconds) is shown in fig. 4 .

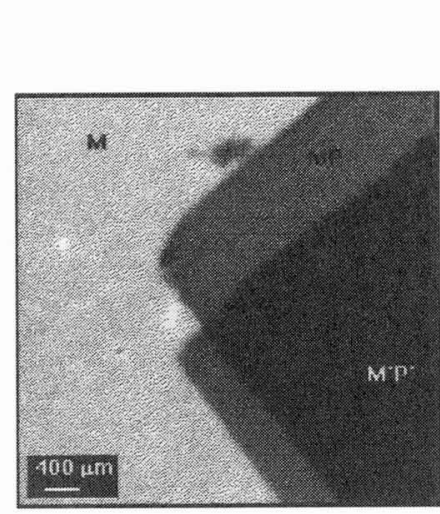

Fig. 2

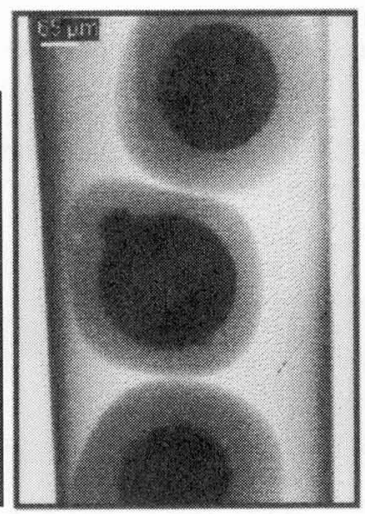

Fig. 3

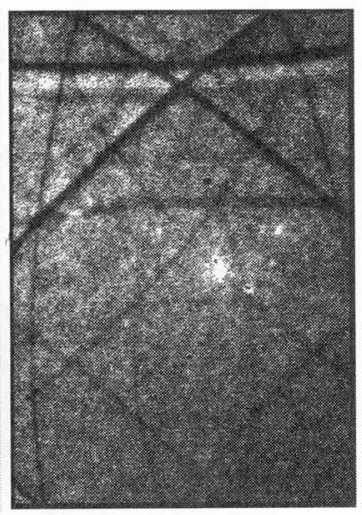

Fig.4

Fig. 2 : X-ray image of a $100 \mu \mathrm{m}$ thick Al sheet partly coated by a $3 \mu \mathrm{m} \mathrm{Cu}$ coating (MP) and a $6 \mu \mathrm{m} \mathrm{Cu}$ coating (M'P'). Image obtained in $15 \mathrm{sec}$ by using a $\mathrm{Cu}$ target $\left(27 \mathrm{keV} ; \mathrm{I}_{\mathrm{O}}=1 \mu \mathrm{A}\right)$.

Fig.3 : Micrograph of $\mathrm{ZrO}_{2}$ balls coated by a SiC layer and set into a glass microtube. V Target exposure time : $30 \mathrm{sec}$.

Fig. 4 : Pseudo Kossel diagram of a LiF single crystal, $460 \mu \mathrm{m}$ thick, using a $\mathrm{Cu}$ target. Exposure time : $5 \mathrm{sec} ; \mathrm{I}_{\mathrm{O}}=1 \mu \mathrm{A} ; \mathrm{E}_{\mathrm{O}}=27 \mathrm{keV}$.

\section{EXAMPLES OF APPLICATION IN MATERIALS SCIENCE}

As mentioned above, the sensitivity of detection of medium elements in light matrices is also illustrated in fig. 5 in the practical case of the investigation of an enlightened (Al, carbon) radiator of a microelectronic device. Fig. 6 provides a similar illustration but related to the intercalation of phosphoric acid, $\mathrm{PO}_{4} \mathrm{H}_{2}$, into lamellar graphite where the detailed inspection of the transmitted intensities (after a logarithmic compression) allows one to calculate the relative concentration (with respect to graphite) of the $\mathrm{PO}_{4} \mathrm{H}_{2}$ molecules for some selected areas (such as points $\mathrm{A}, \mathrm{B}, \mathrm{C}$ ) of the specimen or along some selected profiles [10].

In the case shown in Fig.6, the specimen was set into the vacuum of the microscope at the end of the intercalation process but another experiment has been performed in an electrochemical cell and the progressive intercalation process of $\mathrm{SO}_{4} \mathrm{H}_{2}$ into graphite driven by an applied electric field (between the graphite and the liquid acid) has been followed, step by step, and the time constant of the process has been deduced (paper to be submitted). 


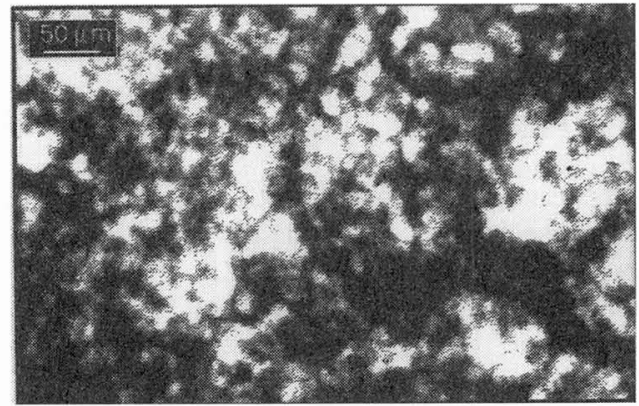

Fig. 5

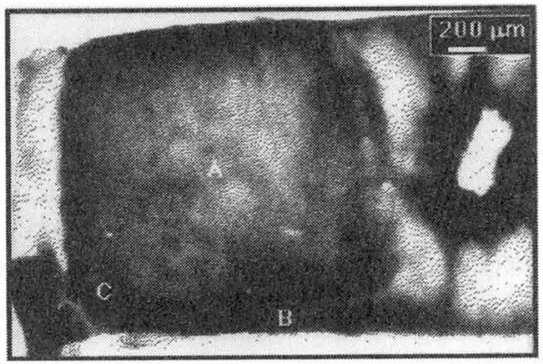

Fig. 6

Fig. 5 : Micrograph of an enlightened radiator for semiconducting devices. This radiator is made of carbon and aluminium. Thickness : $1 \mathrm{~mm}, \mathrm{Ni}$ target ; exposure time : 8 minutes ;

$\mathrm{E}_{\mathrm{O}}=14 \mathrm{keV} ; \quad \mathrm{I}_{\mathrm{O}}=0.2 \mu \mathrm{A}$.

Fig. 6 : Microradiograph of an HOPG matrix $(0.5 \mathrm{~mm}$ thick) showing the beginning of the intercalation process of $\mathrm{PO}_{4} \mathrm{H}_{2}$ (dark regions at the borders of the block) $\mathrm{E}_{\mathrm{o}}=12 \mathrm{keV} ; \mathrm{V}$ target $; \mathrm{I}_{\mathrm{o}}=0.3 \mu \mathrm{A} ; \mathrm{t}=$ $40 \mathrm{sec}$.

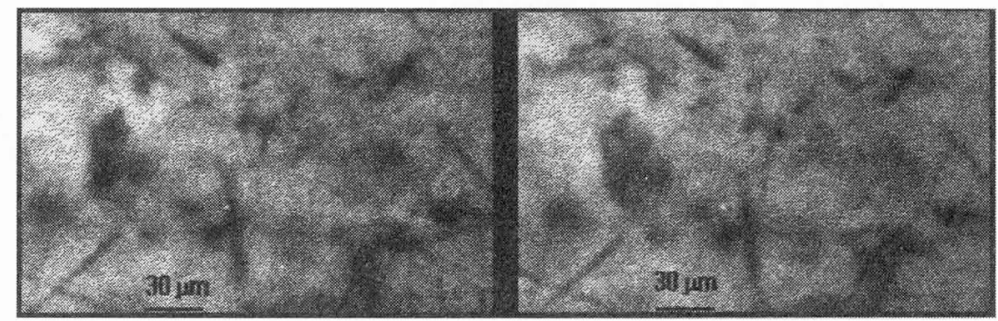

Fig. 7 : Stereo pair image of an AZ61 alloy, $1 \mathrm{~mm}$ thick ; Zr target.
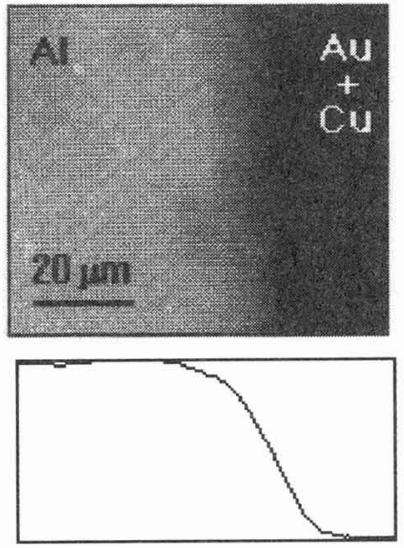

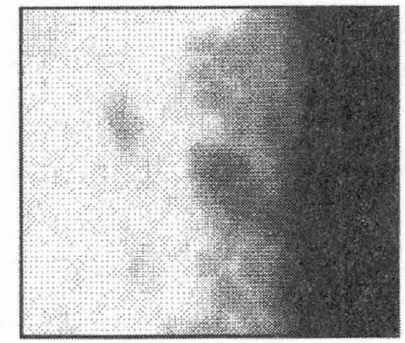

0,86

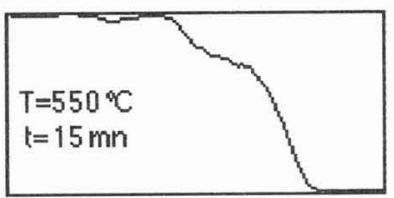

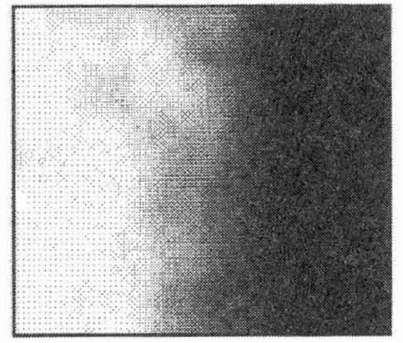

0,87

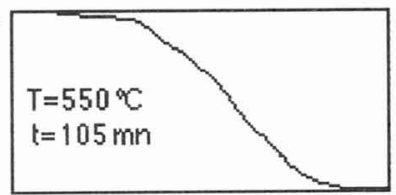

Fig. 8 : Diffusion of $\mathrm{Au}$ and $\mathrm{Cu}$ (in black) into an aluminium matrix. From left to right : initial image ; image obtained after thermal heating during 15 minutes at $550^{\circ} \mathrm{C}$; image obtained after an additional thermal treatment during 1,5 hour. Exposure time for each image : $15 \mathrm{sec}$ (target $\mathrm{Mo} ; \mathrm{I}_{\mathrm{O}}=4.5 \mu \mathrm{A}$; $\mathrm{E}_{\mathrm{O}}=30 \mathrm{keV}$ ). The concentration profiles shown below enable the determination of the diffusion coefficient, $\mathrm{D} \simeq 10^{-10} \mathrm{~cm}^{2} / \mathrm{sec}$. 


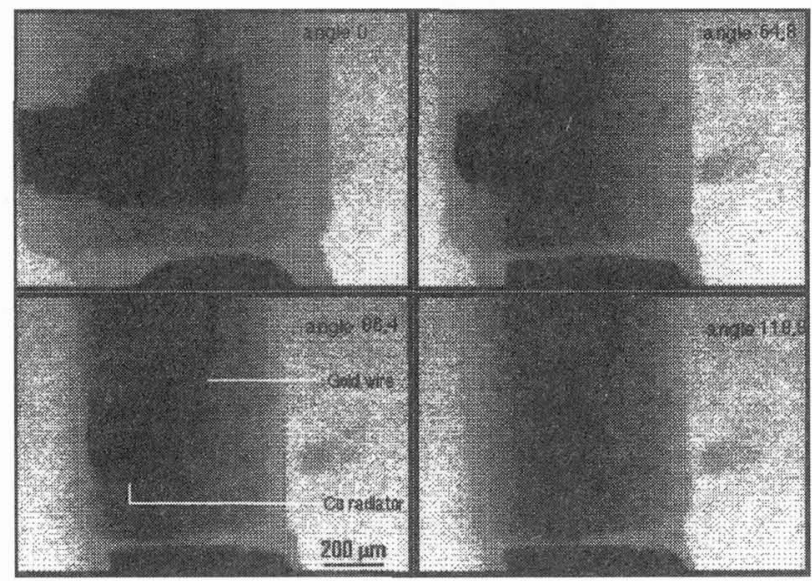

Fig. 9 :Images of an encapsulated silicon diode obtained by rotating the specimen. Such a series of angular views allows to identify the relative positions in the space of the $\mathrm{Cu}$ radiator, the silicon chip and the gold wire connection [13].

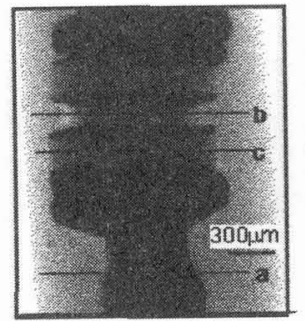

a

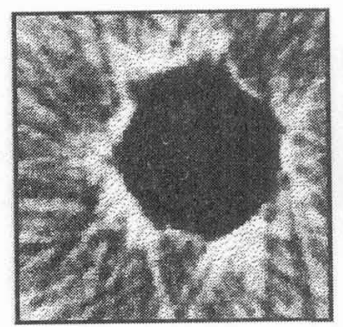

b

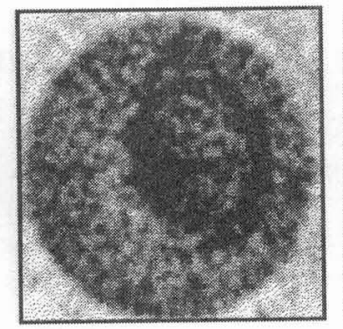

c

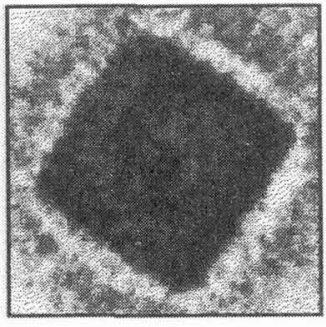

Fig.10 :Example of X-ray microtomography of an encapsulated semiconducting diode [13]. The microradiography on the left represents the position of the three cross-sections (from left to right) : a) the feedthrough ; b) the aluminium electrode ; c) the silicon crystal.

Stereo pairs of images (as those shown in fig.7) may also be easily obtained and their detailed inspection make possible a qualitative estimate of the spatial orientation of the elongated ( $\mathrm{Zn}$, $\mathrm{Mn}$ ) precipitates embedded in a magnesium rich matrix (AZ61 compound).

Solid/solid diffusion studies may also be performed and this possibility is illustrated in Fig. 8 where the diffusion of an $\mathrm{Au} \mathrm{Cu}$ coating into an aluminium matrix is shown. The concentration profiles thus obtained in a direction normal to the interface allows to evaluate rapidly and easily the heterodiffusion coefficient, $D\left(D \simeq\right.$ Fig. $\left.10^{-10} \mathrm{~cm}^{2} / \mathrm{sec}\right)$. This type of experiments seems to us very promising because the phenomenon can be followed in continuity in opposition to the conventional methods (as described by Philibert [11]) used up-to-now for evaluating D.

By simply rotating the specimen and then acquiring (in a few seconds each) successive images at different illumination angles, it is possible to have an idea of the 3-dimensional structure of the specimen. The example of a microelectronic component embedded in its plastic case is shown in Fig. 9 where the relative positions of the $\mathrm{Cu}$ radiator, the silicon chip and the gold wire are easily located [12]. 
Rotating again the specimen with the help of an improved specimen holder, angular series of projections may also be acquired in order to perform X-ray microtomography. By choosing in the image plane, a given line perpendicular to the rotation axis it is possible to select a plane for a cross-section. Reconstructed images of such a cross-section take 30 seconds using an IBM-compatible PC (80486) and a filtered back projection method. In this type of fan beam geometry, the reconstruction procedure was basically that described elsewhere by one of us [13] The resolution of the reconstructed image is in the ten-twenty microns range and it is similar to that obtained by Kinney et al in a recent X-ray tomographic study of vapor infiltration processing of ceramic composites by using a synchrotron radiation source [14]. By showing three different cross-sections of an encapsulated diode, Fig.10 illustrates this approach [12].

\section{CONCLUSION}

In this short review, we have tried to outline that the combination of an old idea (shadow microscopy) with modern technological developments (CCD camera) may offer a renewed method for looking inside materials. This new possibility is easy to operate and it seems to us very promising for the investigation of composite specimens as well as, for example, for solid/solid and solid/liquid dynamical studies. It is the way we are now exploring with the improvement of the 3-dimensional reconstruction methods [15] and the development of quantitative elemental mapping in analytical X-ray microscopy [16].

\section{REFERENCES}

[1] COSSLETT V.E and NIXON W.C., Nature, 168 (1951) 4262

[2] LINDSTROM B., in X-ray Optics and X-ray Microanalysis, Edited by Pattee M.M., Cosslett V.E. and Engstiom A., Academic Press NY (1963) 13

[3] SCHMAHL G. and RUDOLPH D., Editors of X-ray Microscopy Springer Verlag, Berlin, Springer Series in Optical Sciences 43(1984)

[4] SAYRE D., HOWELLS M., KIRZ J., and RARBACK H., Editors of X-ray Microscopy II, Springer Verlag Berlin, Springer Series in Optical Sciences 56 (1987)

[5] MICHETTE A.G., MORRISSON G.R., BUCKLEY C.J., Editors of X-ray Microscopy III, Springer Verlag Springer Series in Optical Sciences 67 (1992)

[6] ADE M., ZHANG X., CAMERON S., COSTELLO C., KIRZ J., and WILLIAMS S. Science 258 (1992) 972

[7] CHENG P.C., SHINOZAKI D.M., LIN T.H., NEWBERRY S.P., SRIDHAR R., TARNG W., CHEN M.T., CHEN L.H., in X-ray Microscopy III. Springer Series in Optical Sciences 67 (1992) 184

[8] ERRE D., MOUZE D., THOMAS X., and CAZAUX J., Inst. Phys. Conf. Series 130 (1993) 567

[9] THOMAS X., CAZAUX J., ERRE D., MOUZE D., COLLARD P., Springer Series in Optical Sciences 67 (1992) 190

[10] ERRE D., Thesis University of Reims (1993) unpublished

[11] PHILIBERT J., Atom movements : Diffusion and mass transport in solids. Les Editions de Physique - Orsay (1991)

[12] SASOV A.Y, and CAZAUX J. Submitted to X-ray Microscopy IV (Moscow 1993)

[13] SASOV A.Y., J. of Microscopy 147 (1987) 169

[14] KINNEY J.H. et al. Science, 260 (1993) 789

[15] ZOLFAGHARI A. and TREBBIA P., Submitted to X-ray Microscopy IV (Moscow 1993)

[16] CAZAUX J., Ultramicroscopy (Submitted to) 